\title{
Pain, depression and sleep disorders in patients with diabetic and nondiabetic carpal tunnel syndrome: a vicious cycle
}

\author{
Dor, depressão e distúrbios do sono em pacientes diabéticos e não diabéticos com \\ síndrome do tumor do carpo: um ciclo vicioso \\ Nermin Tanik', Umit Sarp², Mehmet Ucar, Asuman Celikbilek', Ozlem Balbaloglu³, Hakan Ak', Tugay \\ Atalay 4 , Hasan Onur Arik', Mehmet Yavuz Okyay ${ }^{6}$, Levent Ertugrul Inan
}

\begin{abstract}
Carpal tunnel syndrome (CTS) is a condition involving nerve entrapment that often leads to chronic neuropathic pain. We aimed to evaluate sleep quality and related parameters in diabetic and non-diabetic CTS patients. Method: This study included a total of 366 patients with chronic CTS. These patients' sleep quality was evaluated using the Pittsburgh Sleep Quality Index (PSQI) and depression using the Beck Depression Inventory (BDI). The severity of neuropathic pain was evaluated using the Douleur Neuropathique-4 (DN4) questionnaire and a visual analogue scale (VAS). Results: In the non-diabetic patient group, the total PSQI score was found to affect BDI and VAS, while in the diabetic patient group, the duration of symptoms affected VAS, BDI and fasting glucose levels. Conclusion: For diabetic patients, hyperglycemia depression and chronification of neuropathic pain may lead to deterioration of sleep quality. Therefore, consideration of these parameters in the treatment may break a vicious cycle.
\end{abstract}

Keywords: carpal tunnel syndrome, neuropathic pain, sleep quality, depression, type 2 diabetes.

\section{RESUMO}

A síndrome do túnel do carpo (STC) é uma condição que envolve compressão do nervo frequentemente determinando dor neuropática crônica. Procuramos avaliar a qualidade do sono e parâmetros correlatos em pacientes diabéticos e não-diabéticos com STC. Método: Este estudo incluiu 366 pacientes com STC crônica. A qualidade de sono destes pacientes foi avaliada pelo Pittsburgh Sleep Quality Index (PSQI) e a depressão foi avaliada usando Beck Depression Inventory (BDI). A gravidade da dor neuropática foi avaliada usando o questionário Douleur Neuropathique-4 (DN4) e a escala visual analógica (EVA). Resultados: No grupo de pacientes não-diabéticos, o valor total do PSQI afetou BDI e VAS, enquanto no grupo de diabéticos a duração dos sintomas afetou VAS, BDI e níveis de glicemia de jejum. Conclusão: Em pacientes diabéticos, depressão e cronificação da dor neuropática podem levar à deterioração da qualidade do sono. Assim, considerar todos estes parâmetros no tratamento pode quebrar este círculo vicioso.

Palavras-chave: síndrome do túnel do carpo, dor neuropática, qualidade do sono, depressão, diabetes tipo 2.

Carpal tunnel syndrome (CTS) is the most frequently seen peripheral entrapment neuropathy, which occurs, associated with compression of the median nerve in the wrist. A frequent complaint of these patients is waking from sleep because of pain and numbness in the hand ${ }^{1}$. The reason for increased pain at night is thought to be due to compression of the median nerve in the carpal tunnel with the wrist in a flexion or extension position. Diabetes mellitus is accepted as a risk factor for carpal tunnel patients ${ }^{2}$ and treatment responses are worse compared to non-diabetic patients.

Sleep plays an important role in the regulation of metabolism. Increased pain at night clearly affects the sleep quality of

${ }^{1}$ Bozok University Medical School, Department of Neurology, Yozgat, Turkey;

${ }^{2}$ Yozgat State Hospital, Department of Physical Medicine and Rehabilitation, Yozgat, Turkey;

${ }^{3}$ Bozok University Medical School, Department of Physical Medicine and Rehabilitation, Yozgat, Turkey;

4Bozok University Medical School, Department of Neurosurgery, Yozgat, Turkey;

${ }^{5}$ Yozgat State Hospital, Department of Orthopedics and Traumatology, Yozgat, Turkey;

${ }^{6}$ Bozok University Medical School, Department of Psychiatry, Yozgat, Turkey;

${ }^{7}$ Bozok University Medical School, Department of Neurology, Yozgat, Turkey.

Correspondence: Nermin Tanik; Department of Neurology, Bozok University Medical School, 66200, Yozgat, Turkey; E-mail:drnermin27@hotmail.com

Conflict of interest: There is no conflict of interest to declare.

Received 27 June 2015; Received in final form 20 October 2015; Accepted 10 November 2015. 
CTS patients, whether or not they are diabetic. A relationship has been found between poor sleep quality and the development of diabetes ${ }^{3}$, pain ${ }^{4}$ and depression ${ }^{5}$. Although there have been studies showing the sleep quality of CTS patients and diabetes ${ }^{3,6}$, there have been no studies evaluating the sleep quality of CTS patients both with and without diabetes. This study aimed to investigate the relationship between sleep quality, depression and chronic pain in chronic carpal tunnel syndrome patients with diabetes and without diabetes.

\section{METHOD}

\section{Study population}

This prospective study comprised 366 patients who had been directed to the neurology polyclinic with an initial diagnosis of carpal tunnel syndrome, which was confirmed by neurological examination and EMG evaluation and symptoms had been ongoing for one years. Of the total 366 patients, 122 were diabetic (type 2) and 244 were non diabetic. Approval for the study was granted by Bozok University Medical Faculty Ethics Committee. Informed consent was obtained from all the patients. Exclusion criteria were pregnancy, vitamin B12 deficiency, systemic or metabolic diseases, a history of trauma or surgery to the hand, alcohol or drug dependency and serious psychiatric disorders. Routine hematological and biochemical analyses including glycated hemoglobin (HbAlc) were applied to the patients. The height and weight of each patient was measured and body mass index (BMI) was calculated. The calculated BMI values were grouped using the World Health Organization classification?

\section{DN4}

To evaluate neuropathic pain in the patients, the Douleur Neuropathique 4 Questions (DN4) scale was applied. This has 7 headings related to symptoms, 4 questions for neuropathic pain and 3 related to neurological examination. From a possible total of 10 points, a score over 4 indicates neuropathic pain ${ }^{8}$.

\section{VAS}

To measure the severity of pain a Visual Analogue Scale (VAS) was used. This measures pain along a $100 \mathrm{~mm}$ horizontal scale with 0 defined as no pain and 100 as the maximum pain imaginable and patients subjectively indicate the waking point of pain ${ }^{9}$.

\section{Pittsburgh Sleep Quality Index}

To evaluate the sleep quality of the patients within the previous month, the PSQI was used ${ }^{10,11}$. This index has been tested for validity and reliability in the Turkish population ${ }^{12}$. The index consists of 19 questions and 7 components of subjective sleep quality sleep latency, sleep duration, habitual sleep efficiency, sleep disturbances, use of sleeping medication and daytime dysfunction. Each question is evaluated on 0-3 points and the total points of the 7 components give the global PSQI score, which may be a value between 0 and 21. A global PSQI score of 5 or below indicates that sleep quality is good and a score of above 5 indicates poor sleep quality.

\section{Beck Depression Inventory}

This scale is used to define the risk of depression in adults and to measure changes in the severity and level of depression symptoms. It is a self-assessment scale consisting of 21 items related to depression symptoms. Each item is scored between 0 and 3, giving a total of between 0 and 63 . The scale has been tested for validity and reliability in the Turkish population ${ }^{13}$.

\section{Electrophysiological evaluation}

This evaluation was made according to the protocol recommended for CTS by the American Electro diagnostic Medical Association and American Physical Medicine and Rehabilitation Academy, using standard nerve transmission techniques with surface electrodes on a Medelec Synergy device ${ }^{14}$. According to this protocol, Mild CTS is classified as Median SCV slowed in the finger-wrist tract with normal DML, Moderate CTS as Median SCV slowed in the fingerwrist tract with increased DML and Severe CTS as the absence of median sensory response in the finger-wrist tract with increased DML. The median and ulnar nerve motor and sensory nerve transmission speed was evaluated in both hands. Skin temperature was maintained at $>32^{\circ} \mathrm{C}$ on the dorsum of the hand.

\section{Statistical analysis}

Descriptive statistics included medians, standard deviations, percentages and minimum/maximum range. The independent-sample t-test was used to compare differences between continuous variables, and $C h i$-square $\left(\chi^{2}\right)$ analysis was used to assess differences between categorical variables. Correlations between parameters were tested with the Pearson correlation test as appropriate. A value of $p<0.05$ was regarded as significant in all statistical analyses. The values are presented as mean $\pm 95 \%$ confidence interval unless otherwise stated. Data were analyzed with SPSS 16.0 software.

\section{RESULTS}

The socio demographic and laboratory data of the diabetic and non-diabetic CTS patients obtained with the scales used in the study are summarized in Table 1. No significant difference was determined between the two groups in respect of age, gender, severity of CTS and duration of CTS symptoms ( $p>0.05)$, but a difference was determined in respect of BMI 
Table 1. Demographic and laboratory data of non-diabetic and diabetics carpal tunnel syndrome (CTS) patients.

\begin{tabular}{|c|c|c|c|}
\hline & Non-Diabetic CTS & Diabetic CTS & $\mathrm{p}$ \\
\hline Age (years) & $51 \pm 11.5$ & $53 \pm 10.1$ & 0.06 \\
\hline Sex $(F / M)$ & $208 / 35$ & $104 / 18$ & 0.92 \\
\hline $\mathrm{BMI}\left(\mathrm{kg} / \mathrm{m}^{2}\right)$ & $31.8 \pm 5.1$ & $33.8 \pm 5.3$ & $0.001^{*}$ \\
\hline Duration of symptoms (years) & $3.0 \pm 1.0$ & $3.1 \pm 0.9$ & 0.75 \\
\hline Diabetes duration (years) & & $8.7 \pm 7.5$ & \\
\hline CTS severity & $1.5 \pm 0.5$ & $1.5 \pm 0.6$ & 0.76 \\
\hline Effected size (bilateral/unilateral) & $165 / 79$ & $101 / 21$ & $0.02^{*}$ \\
\hline VAS & $8.0 \pm 1.2$ & $7.9 \pm 1.1$ & 0.26 \\
\hline DN4 & $8.3 \pm 6.0$ & $7.7 \pm 1.6$ & 0.14 \\
\hline $\mathrm{BDI}$ & $22.0 \pm 10.8$ & $21.6 \pm 11.7$ & 0.77 \\
\hline Global PSQI & $7.3 \pm 3.9$ & $7.1 \pm 4.1$ & 0.71 \\
\hline Fasting glucose (mg/dL) & $99.3 \pm 11.3$ & $170.2 \pm 72.2$ & $0.001^{*}$ \\
\hline HbA1c (\%) & $5.6 \pm 0.4$ & $7.8 \pm 1.5$ & $0.001 *$ \\
\hline
\end{tabular}

values $(p<0.05)$. In addition no significant difference was determined between the two groups in terms of VAS, DN4, Global PSQI score and BDI values ( $p>0.05)$. Bilateral CTS, fasting glucose and $\mathrm{HbAlc}$ levels were found to be statistically significantly higher in the diabetic patient group $(\mathrm{p}<0.05)$. In the diabetic patient group a significant correlation was determined between the duration of symptoms $(p<0.05)$, VAS $(\mathrm{p}<0.001)$, BDI $(\mathrm{p}<0.001)$ and fasting glucose $(\mathrm{p}<0.001)$ (Table 2). In the non-diabetic patient group, a significant correlation was determined between the Global PSQI score and depression $(p<0.001)$ and VAS $(p<0.05)($ Table 3$)$.

\section{DISCUSSION}

In this study, no correlation was determined between sleep quality and the severity of CTS electro physiologically, but there was a correlation with VAS. In both groups, the most important factor affecting sleep quality was found to be depression. In diabetic patients, fasting glucose and the duration of symptoms were found to affect sleep quality.

Table 2. Factors affecting global Pittsburg sleep quality index (PSQI) score in diabetic patients.

\begin{tabular}{lcc}
\hline Diabetic CTS Global PSQI $(n=122)$ & $p$ & $r$ \\
\hline Duration of symptoms & $0.01^{*}$ & 0.21 \\
VAS & $0.009 *$ & 0.23 \\
BDI & $<0.001 *$ & 0.33 \\
Fasting glucose $(\mathrm{mg} / \mathrm{dL})$ & $0.01^{*}$ & 0.21 \\
\hline VAS: visual analog scale; BDI: beck depression index; *statically difference.
\end{tabular}

Table 3. Factors affecting global Pittsburg sleep quality index (PSQI) score in non-diabetic patients.

\begin{tabular}{lcc}
\hline Non-Diabetic CTS Global PSQI $(n=244)$ & $p$ & $r$ \\
\hline VAS & $0.03^{*}$ & 0.13 \\
BDI & $<0.001^{*}$ & 0.55 \\
\hline
\end{tabular}

VAS: visual analog scale; BDI: beck depression index; *statically difference.
Sleep is an important part of the biological rhythm and it completes a healthy biological cycle. Poor sleep quality has been found to be related to several diseases (hypertension, obesity, cardiovascular diseases) and particularly with insulin resistance ${ }^{15}$. Neuropathic pain seen in patients with carpal tunnel syndrome shows an increase at night in particular. This clearly triggers disturbed sleep in the patient. Decreased quality of sleep has a direct effect on daily living activities and emotional status ${ }^{16,17}$. The quality of life of the patient is significantly affected both by the pain itself and by the subsequent sleep and emotional status impairments ${ }^{18}$.

In both groups of the current study, no correlation was determined between sleep quality and the severity of CTS electro physiologically but a significant correlation was determined with VAS. Only one study has investigated the relationship of CTS severity with sleep quality. In that study, Patel et al. ${ }^{6}$ determined a negative correlation between CTS severity and sleep quality. As the CTS severity was evaluated in that study with VAS-pain and the Boston Carpal Tunnel Questionnaire, a correlation was not made with CTS severity in an electrophysiological evaluation. To the best of our knowledge, the current study is the first in literature to evaluate the relationship between electrophysiological CTS severity and sleep quality. The mean duration of symptoms in the current study was 2-4 years, which shows a period of chronic pain in the patients. It has been suggested that in patients with chronic pain, sleep deprivation lowers the pain threshold and hyperalgesia occurs ${ }^{19}$. This would explain why patients in the current study had high VAS scores (mean 8 ), despite almost half $(48,6 \%)$ being determined with mild CTS in the electrophysiological evaluation. In a similar study by Nicholson and Verma, using the Brief Pain Inventory to evaluate pain, the severity of pain was determined to be correlated with sleep disturbance ${ }^{20}$. Therefore, when treating patients, especially if the pain has become chronic, it can be considered more important to consider the severity of pain felt by the patient rather than the electrophysiological severity of CTS. 
The most common psychiatric disorder accompanying neuropathic pain is depression. In the current study, depression was determined to be the most significant factor affecting sleep quality in patients with chronic neuropathic pain. Similar to the current study, several studies have been conducted on the relationship between depression and chronic pain $^{21,22}$. Pain is likely to lead to depression, which lowers the pain threshold and can make the pain more intolerable. The mechanisms of acute and chronic pain are thought to be different. Chronic pain can lead to permanent changes in the brain structure and functions. This process has developed new intra and intercortical connections associated with the reorganization of cortical functions and structures ${ }^{23}$. Several common mechanisms are found between chronic pain and depression. In the common pathophysiological mechanism of both, serotonergic, noradrenergic and glutamergic systems play a role. A decrease in serotonin metabolites has been observed to cause both a worsening of depression symptoms and an increase in pain sensation. In neuropathic pain, noradrenaline is one of the most important neurotransmitters in the flow of the descending inhibitor pathway from the brain to the spinal cord. A decrease in noradrenaline levels is one of the characteristic properties of depression. Increased glutamate expression is a basic stage in central sensitization of chronic pain and depression ${ }^{24}$. Using common mechanisms, a vicious circle is created of chronic pain leading to depression and depression leading to pain sensitivity.

Several factors play a role in neuropathy pathogenesis in diabetic patients, but the most important factor is hyperglycemia. Small increases in glucose levels cause peripheral nerve damage ${ }^{25}$. To be able to provide good metabolic control, particularly in the first 8 years of diabetes, even if $\mathrm{HbAlc}$ increases, neuropathy can be prevented ${ }^{26}$. In the current study, hyperglycemia and the duration of symptoms were found to have affected sleep quality in the diabetic patients. Hyperglycemia, which affects the development of neuropathy, also affects sleep quality. We believe there may be a two-way relationship between hyperglycemia and sleep quality. Hyperglycemia may result in impaired sleep quality, just as it may be associated with uncontrolled diabetes. Hyperglycemia triggers sleep disturbance and sleep disturbance triggers hyperglycemia. Recent studies have shown sleep disturbance to be an independent risk factor in the development and worsening of insulin resistance. Therefore, in the treatment of sleep disorders, providing glycogenic control in diabetic patients has been proposed as an additional strategy ${ }^{27,28}$. In neurology practice, only neuropathic pain is treated in most neurology patients and co-morbidities are not taken into consideration. Haythornthwaite et al. developed a sleep diary to be used by patients with chronic pain. The evaluation of sleep quality using the results obtained in the sleep diary has been found to be an extremely simple and effective method $^{29}$. To be able to evaluate depression in patients with pain, a simple scanning tool such as the BDI can be used to make a quick initial evaluation as to whether the patient is depressed or not by asking two questions: 1) during the past month, have you often been bothered by feeling down, depressed, or hopeless? And 2) during the past month, have you often been bothered by having little interest or pleasure in doing things $?^{30}$.

The success rate is low in the treatment of neuropathic pain. That sleep disturbance and depression are not taken into consideration is thought to have an effect on the low success rate. Physicians should also be aware that when neuropathic pain becomes chronic, this creates difficulties in the treatment process. Particularly in diabetic patients, depression and sleep disturbance are thought to increase other diabetic complications such as neuropathic pain.

There were some limitations to the current study. The first is that polysomnography (PSG) is the gold standard for the evaluation of sleep. Thus, sleep evaluation of the patients could have been made with PSG. The second is that there could have been an investigation into the relationship between factors affecting sleep quality and insulin resistance in diabetic patients.

In conclusion, for the effective treatment of neuropathic pain, consideration of parameters affecting sleep quality may improve patients suffering. 
1. Wainner RS, Fritz JM, Irrgang JJ, Delitto A, Allison S, Boninger ML. Development of a clinical prediction rule for the diagnosis of carpal tunnel syndrome. Arch Phys Med Rehabil. 2005;86(4):609-18. doi:10.1016/j.apmr.2004.11.008

2. Jenkins PJ, Duckworth AD, Watts AC, McEachan JE. The outcome of carpal tunnel decompression in patients with diabetes mellitus. J Bone Joint Surg Br. 2012;94(6):811-4 . doi:10.1302/0301-620X.94B6.29174

3. Byberg S, Hansen AL, Christensen DL, Vistisen D, Aadahl M, Linneberg A et al. Sleep duration and sleep quality are associated differently with alterations of glucose homeostasis. Diabet Med. 2012;29(9):e354-60. doi:10.1111/j.1464-5491.2012.03711.x

4. Zarrabian MM, Johnson M, Kriellaars D. The relationship between sleep, pain and disability in patients with spinal pathology. Arch Phys Med Rehabil. 2014;95(8):1504-9.doi:10.1016/j.apmr.2014.03.014

5. Roane BM, Johnson L, Edwards M, Hall J, Al-Farra S, O'Bryant SE. The link between sleep disturbance and depression among Mexican Americans: a Project FRONTIER study. J Clin Sleep Med. 2014;10(4):427-31. doi:10.5664/jcsm.3622

6. Patel A, Culbertson MD, Patel A, Hashem J, Jacob J, Edelstein D et al. The negative effect of carpal tunnel syndrome on sleep quality. Sleep Disord. 2014;2014:962746. doi:10.1155/2014/962746

7. World Health Organization. WHO Expert Committee on Physical Status: the use and interpretation of anthropometry. Geneva: World Health Organization; 1995. (WHO Technical Report Series, Vol. 854).

8. Bouhassira D, Attal N, Alchaar H, Boureau F, Brochet B, Bruxelle $J$ et al. Comparison of pain syndromes associated with nervous or somatic lesions and development of a new neuropathic pain diagnostic questionnaire (DN4). Pain. 2005;114(1-2):29-36. doi:10.1016/j.pain.2004.12.010

9. Melzack R. The short-form McGill Pain Questionnaire. Pain. 1987;30(2):191-7. doi:10.1016/0304-3959(87)91074-8

10. Buysse DJ, Reynolds CF 3rd, Monk TH, Berman SR, Kupfer DJ. The Pittsburgh Sleep Quality Index: a new instrument for psychiatric practice and research. Psychiatry Res. 1989;28(2):193-213. doi:10.1016/0165-1781(89)90047-4

11. Buysse DJ, Reynolds CF 3rd, Monk TH, Hoch CC, Yeager AL, Kupfer DJ. Quantification of subjective sleep quality in healthy elderly men and women using the Pittsburgh Sleep Quality Index (PSQI). Sleep. 1991;14(4):331-8.

12. Ağargün $\mathrm{YM}, \mathrm{Kara} \mathrm{H}$, Anlar $\mathrm{O}$. The validity and reliability of the pittsburgh sleep quality Index. Turkish J Psych. 1996;7:107-11.

13. Hisli N. A study on the validity of Beck Depression Inventory. Turkish $J$ Psych. 1987;6:118-22.

14. American Academy of Neurology, American Association of Electrodiagnostic Medicine and American Academy of Physical Medicine and Rehabilitation. Practice parameter for electrodiagnostic studies in carpal tunnel syndrome (summary statement). Neurology. 1993;43(11):2404-5. doi:10.1212/WNL.43.11.2404

15. Buxton OM, Pavlova M, Reid EW, Wang W, Simonson DC, Adler GK. Sleep restriction for 1 week reduces insulin sensitivity in healthy men. Diabetes. 2010;59(9):2126-33. doi:10.2337/db09-0699
16. Annagür BB, Uguz F, Apiliogullari S, Kara I, Gunduz S. Psychiatric disorders and association with quality of sleep and quality of life in patients with chronic pain: A SCID-Based Study. Pain Med. 2014;15(5):772-81. doi:10.1111/pme.12390

17. Alsaadi SM, McAuley JH, Hush JM, Bartlett DJ, McKeough ZM, Grunstein RR et al. Assessing sleep disturbance in low back pain: the validity of portable instruments. PLoS One. 2014;9(4):e95824. doi:10.1371/journal.pone.0095824. eCollection 2014

18. Stewart WFRJ, Chee E, Brandenberg N. Work related costs of diabetic neuropathic (DPN) Pain in the US: results from the american productivity audit. In: 24th Annual Scientific Meeting of the American Pain Society; 2014; Boston, Mass.

19. Schuh-Hofer S, Wodarski R, Pfau DB, Caspani O, Magerl W, Kennedy JD et al. One night of total sleep deprivation promotes a state of generalized hyperalgesia: a surrogate pain model to study the relationship of insomnia and pain. Pain. 2013;154(9):1613-21. doi:10.1016/j.pain.2013.04.046

20. Nicholson B, Verma S. Comorbidities in chronic neuropathic pain. Pain Med. 2004;5(Suppl s1):s9-27. doi:10.1111/j.1526-4637.2004.04019.x

21. Bouhassira D, Letanoux M, Hartemann A. Chronic pain with neuropathic characteristics in diabetic patients: a French cross-sectional study. PLoS One. 2013;8(9):e74195. doi:10.1371/journal.pone.0074195. eCollection 2013

22. Radat F, Margot-Duclot A, Attal N. Psychiatric co-morbidities in patients with chronic peripheral neuropathic pain: a multicentre cohort study. Eur J Pain. 2013;17(10):154-7. doi:10.1002/j.1532-2149.2013.00334.x

23. Apkarian AV. The brain in chronic pain: clinical implications. Pain Manag. 2011;1(6):577-86. doi:10.2217/pmt.11.53

24. Nekovarova T, Yamamotova A, Vales K, Stuchlik A, Fricova J, Rokyta R. Common mechanisms of pain and depression: are antidepressants also analgesics? Front Behav Neurosci. 25 Mar 2014. doi:10.3389/fnbeh.2014.00099

25. Ziegler D, Rathmann W, Dickhaus T, Meisinger C, Mielck A. Prevalence of polyneuropathy in pre-diabetes and diabetes is associated with abdominal obesity and macroangiopathy: the MONICA/KORA Augsburg Surveys S2 and S3. Diabetes Care. 2008;31(3):464-9. doi:10.2337/dc07-1796

26. Nathan DM, Cleary PA, Backlund JY, Genuth SM, Lachin JM, Orchard TJ et al. Intensive diabetes treatment and cardiovascular disease in patients with type 1 diabetes. N Engl J Med. 2005;353(25):2643-53. doi:10.1056/NEJMoa052187

27. Van Cauter E. Sleep disturbances and insulin resistance. Diabet Med. 2011;28(12):1455-62. doi:10.1111/j.1464-5491.2011.03459.x

28. Engeda J, Mezuk B, Ratliff S, Ning Y. Association between duration and quality of sleep and the risk of pre-diabetes: evidence from NHANES. Diabet Med. 2013;30(6):676-80. doi:10.1111/dme.12165

29. Haythornthwaite JA, Hegel MT, Kerns RD. Development of a sleep diary for chronic pain patients. J Pain Symptom Manage. 1991;6(2):65-72. doi:10.1016/0885-3924(91)90520-E

30. Gallagher RM, Verma S. Treatment and rehabilitation of chronic orthopedic pain syndromes. In: Stoudemire A, Fogel B, Greenblatt D, editors. Psychiatric care of the medical patient. New York: Oxford; 1999. 